\title{
Spatial and temporal variations in albedo on Storglaciären, Sweden
}

\author{
Ulf JONSELL, ${ }^{1}$ Regine HOCK, ${ }^{1}$ BJörn HOLMGREN ${ }^{2}$ \\ ${ }^{1}$ Department of Physical Geography and Quaternary Geology, Stockholm University, SE-106 91 Stockholm, Sweden \\ E-mail: ulf.jonsell@natgeo.su.se \\ ${ }^{2}$ Abisko Scientific Research Station, SE-98107 Abisko, Sweden
}

\begin{abstract}
Extensive albedo data from Storglaciären, Sweden, during nine summers are analyzed, focusing on the effect of surface slope on measurements and on the influence of clouds on albedo of both snow and ice surfaces. On clear-sky days, albedo continuously dropped throughout the day by $>0.3$ when derived from measurements in a horizontal plane over the slightly sloping surface. When we correct for the tilt effect, over frozen surfaces the apparent decrease in albedo largely disappeared, while over melting surfaces it became significantly less pronounced. This emphasizes the need to correct horizontally measured data for slope when they are used, for example, as ground truth for satellite-derived albedo, or in high-resolution glacier melt runoff models. Albedo varied by $>0.1$ due to cloud fluctuations. To quantify cloud effects, albedo changes between successive (half-) hourly and daily data were regressed against corresponding changes in cloudiness expressed by the ratio of global radiation to top-of-atmosphere solar radiation. The resulting relationship over snow explains $66 \%$ of oberved albedo changes using hourly, and $42 \%$ using daily, time-steps. Over ice, the corresponding values are $28 \%$ and $0 \%$. Hence, cloudiness is a dominating factor in determining short-term variability of albedo over snow, whereas over ice the observed large day-to-day variability $(>20 \%)$ is mainly attributed to changes in the physical characteristics of the weathering crust. Results suggest that cloud effects should be incorporated into models treating snow and ice surfaces separately.
\end{abstract}

\section{INTRODUCTION}

Since shortwave radiation often plays a dominant role in the surface energy budget of snow and ice, albedo plays a crucial role in glacier melt and Earth-atmosphere energy exchange. Many authors have demonstrated the role of albedo in glacier mass balance. For example, Van de Wal and others (1992) found that differences in ablation on the tongue of Hintereisferner, Austria, were almost entirely due to differences in surface albedo. Oerlemans and Hoogendoorn (1989) simulated a change in equilibrium-line altitude of $>200 \mathrm{~m}$ in response to a 0.1 albedo perturbation for a fictitious glacier at Sonnblick, Austria, considerably exceeding the simulated change due to a $1 \mathrm{~K}$ temperature perturbation.

Albedo is generally defined as the spectrally integrated reflectivity over the shortwave spectrum from 0.35 to $2.8 \mu \mathrm{m}$. Surface albedo on a glacier can vary spatially from $<0.1$ for sediment-rich ice to $>0.9$ for fresh snow (see summary in Müller, 1985; Cutler and Munro, 1996). Glacier albedo variations occur on many time-scales (e.g. the seasonal scale, as the surface type changes from snow to ice and vice versa; or changes within minutes as a result of varying atmospheric conditions, such as cloud cover). The controls of albedo can be divided into two categories: (1) those related to characteristics of the surface layer (e.g. grain-size, impurity content, surface roughness), and (2) those related to properties of incident radiation and atmospheric factors (e.g. wavelength or whether the sunlight is direct or diffuse
(Marshall and Warren, 1987)). The enormous spatial and temporal variability in albedo, combined with the complex interplay of different factors determining albedo, renders the modelling of glacier albedo inherently difficult, hence the large variety of albedo parameterizations proposed in melt and mass-balance models (see summary in Brock and others, 2000). Recently, in order to better capture the large spatial variability, an increasing number of studies have focused on the retrieval of surface albedo from satellite data (e.g. Knap and others, 1999b; Greuell and Knap, 2000). However, major drawbacks in this method are the limited temporal resolution given by low satellite return periods, restriction to cloudless conditions and retrieval problems arising from topographic effects on reflected radiation.

Although a large variety of studies have focused on snow albedo and its modelling (e.g. Dirmhirn and Eaton, 1975; Wiscombe and Warren, 1980; Warren, 1982; Grenfell and others, 1994), only a few have dealt with the specific conditions on glaciers characterized by the coexistence of snow and ice surfaces partially overlain by sediment and debris (Müller, 1985; Oerlemans, 1992; Cutler and Munro, 1996; Oerlemans and Knap, 1998; Arendt, 1999; Brock and others, 2000). This paper analyzes albedo data collected over ice and snow surfaces on Storglaciären, a small valley glacier in Sweden, during nine melt seasons between 1976 and 2000. The specific objectives are (1) to report on the temporal and spatial variations in surface albedo on the glacier, (2) to quantitatively demonstrate the effect of surface slope on 
horizontally measured albedo, and (3) to analyze and quantify the different effects clouds have on the albedo of snow vs ice surfaces.

\section{BACKGROUND}

\subsection{Diurnal variation and effect of surface slope}

Diurnal variation of snow and ice albedo is a matter of much discussion. Variations on overcast days are usually negligible, whereas significant variations of $>0.3$ have been found on clear-sky days (Sauberer and Dirmhirn, 1952; Hubley, 1955; Dirmhirn and Eaton, 1975; Wendler and Kelley, 1988; Konzelmann and Ohmura, 1995). However, timing of minima and maxima varies considerably among different studies, as both the characteristics of incident radiation and surface properties may change during the day, and different factors may dominate in different areas and at different times. Higher albedo at low sun-altitude angles has been reported in many studies (e.g. Ambach, 1963; Müller, 1985; Cutler and Munro, 1996) and can largely be explained by the Mie scattering properties of ice grains dominating other effects such as the spectral change in incoming radiation (Warren, 1982). Holmgren (1971), Ohmura (1981), Müller (1985) and Sicart and others (2001) argue that much of the observed diurnal variation is a pseudo-variation when the measuring device is mounted horizontally instead of parallel to the inclined glacier surface. Mannstein (1985) and Grenfell and others (1994) presented correction formulas and showed the impact of various slope and slope azimuth angles on horizontally measured albedo.

Despite the large impact on observed diurnal variations, even for small slope angles, this effect has seldom been discussed, and often is ignored in the glaciological literature. We therefore pay special attention to this aspect. Diurnal albedo variation in itself is generally not considered relevant with respect to longer-term glacier mass-balance variations. However, Arendt (1999) showed that neglecting diurnal albedo variations on John Evans Glacier, Canada, changed the seasonal net shortwave radiation by up to $16 \%$, and concluded that diurnal albedo variations may be important for accurate simulation of the mass balance of Arctic glaciers. In addition, the proper albedo value at a specific point in time is of major importance from the perspective of remote sensing, when comparing satellite-derived albedo with field measurements (e.g. Knap and others, 1999a; Reijmer and others, 1999). Awareness of diurnal variations in albedo caused by the tilt effect is also required when using direct albedo measurements as input in high-resolution glacier melt run-off models (e.g. Hock and Noetzli, 1997; Escher-Vetter, 2000), since diurnal albedo variations affect the shape of glacier meltwater runoff cycles, and thus the timing of daily peak meltwater production.

\subsection{Effect of clouds}

Snow albedo normally increases with increasing cloudiness, as observed by Olsson (1936). The proportion of visible light is enhanced, since clouds, snow and ice surfaces preferentially absorb near-infrared radiation. Consequently albedo increases, as the visible spectrum has much higher reflectivity than the near-infrared (Wiscombe and Warren, 1980; Warren, 1982). This effect is enhanced by multiple reflection between the cloud base and the snow or ice surface. Cutler and Munro (1996) found a rise in snow reflectivity under increasing cloud for the near-infrared part of the spectrum, further contributing to the overall increase in albedo with cloudiness. Snow albedos have been found to be 3-15\% higher on overcast days compared to clear-sky days (Liljequist, 1956; Holmgren, 1971; Carroll and Fitch, 1981; Wendler and Kelley, 1988; Winther, 1993; Konzelmann and Ohmura, 1995). Under foggy conditions, Hubley (1955) reported a 30\% increase.

While the effect of clouds on the albedo of snow has long been demonstrated on grounds of observational and theoretical evidence, surprisingly few studies have addressed the issue over glacier ice surfaces. To our knowledge, there is no reported study quantifying the cloud effect over glacier ice in comparison to snow surfaces. Although indicating a lack of dependency, or a lower dependency, of ice albedo on total cloud amount compared to that of snow surfaces (Konzelmann and Ohmura, 1995; Bintanja and Van den Broeke, 1996; Key and others, 2001), previous studies suffer from one or more of the following shortcomings: snow and ice surfaces are not clearly distinguished; the database over ice is slim; analysis is limited to plotting daily albedo means against cloud-cover observations, making it difficult to unravel the cloud effect from other influencing factors. Analyzing cloud dependence individually for the visible $(0.35-0.695 \mu \mathrm{m})$ and near-infrared $(0.695-2.8 \mu \mathrm{m})$ spectral bands, Cutler and Munro (1996) found the response to increased cloudiness to be smaller over ice than over snow. However, the authors do not report the overall effect on broadband albedo. The cloud effect is generally neglected in albedo parameterizations in glacier melt models. Greuell and Oerlemans (1986) and Greuell and Konzelmann (1994) include it, but do not differentiate between snow and ice surfaces. The vast amount of data on Storglaciären provides us with the unique opportunity to carefully select sufficient cases to isolate and quantify the effect of clouds for snow and ice surfaces separately.

Cloud dependence of albedo poses a problem for retrieving larger-scale albedo over snow and ice by remote sensing, since satellite-derived albedo data can only be collected under clear-sky conditions. Quantification of the cloud effect on albedo is also important for predicting large-scale effects of future global warming on the cryosphere. Since changes in cloudiness are possible effects (Garratt and others, 1999), incorporating cloud dependency into such models is important to properly account for albedo feedbacks.

\section{SITE DESGRIPTION}

Storglaciären is located in Swedish Lapland $\left(67^{\circ} 55^{\prime} \mathrm{N}\right.$, $18^{\circ} 35^{\prime} \mathrm{E}$ ). It covers an area of $3.1 \mathrm{~km}^{2}$ (Fig. 1) from 1120 to $1730 \mathrm{~m}$ a.s.l. It is orientated to the east, with precipitous walls rising above the accumulation area. The climate is characterized by frequent cyclonic activities. Annual mean air temperature (1965-87) at the Tarfala Research Station, $1 \mathrm{~km}$ northeast of the glacier (1130 m a.s.l.), is $-4.1^{\circ} \mathrm{C}$ (Grudd and Schneider, 1996). Energy-balance studies for the 1993 and 1994 melt seasons indicated that on average net radiation was the main contributor to the energy available for melt, whilst one-third to almost half of the melt energy is provided by turbulent heat fluxes (Hock and Holmgren, 1996; Hock, 1998).

\section{FIELD MEASUREMENTS}

Comprehensive glacio-meteorological experiments were 
albedo was measured on 11 days between 18 July and 2 September (Fig. 1). All measurements were conducted within 0900-1400 h local standard time. The albedometer was mounted on a tripod, with the rod holding the albedometer $1 \mathrm{~m}$ from the tripod head and in the slope azimuth direction. Measurements were taken in a surface-parallel plane. To overcome microtopography, the surface slope was determined with an inclinometer along a $3 \mathrm{~m}$ long pole laid out on the surface in the slope azimuth direction upslope of each stake. The albedometer signals were scanned at $5 \mathrm{~s}$ intervals by a data logger, recording a $1 \mathrm{~min}$ average. Cloud cover and surface type were noted for each measurement.

The surface slopes around the AWSs were determined by inclinometers in the 1970s and by traditional surveying or global positioning system (GPS) measurements in the 1990s. Slopes ranged from almost zero (AWS F) to roughly $10^{\circ}$ (AWS A), and slope azimuth angles for all stations were close to $90^{\circ}$.

\section{DATA TREATMENT}

Half-hourly or hourly albedo values were only computed when the zenith angle was $<65^{\circ}$, to avoid periods with low shortwave radiative fluxes and because of lower accuracy of measurements for large zenith angles. Daily means were computed by integrating global and reflected shortwave radiation for the entire day. The dataset was carefully scrutinized, and any data potentially subject to errors (e.g. by instrument tilt; snow cover on upfacing dome) were either eliminated or corrected. When albedo apparently exceeded 1 , new snowfall was assumed. In these cases, measured global radiation was corrected to an albedo of 0.9 , a value generally assumed for fresh snow (Paterson, 1994).

Albedo values were corrected for the error introduced by installing the pyranometer horizontally instead of parallel to the sloping surface, applying the following correction scheme. True albedo, $\alpha_{\mathrm{t}}$, is given by

$$
\alpha_{\mathrm{t}}=\frac{R_{\mathrm{s}}}{G_{\mathrm{s}}}
$$

where $R$ is reflected shortwave radiation and $G$ is global radiation, the subscript $\mathrm{s}$ referring to receivers parallel to the inclined surface. We thus need to derive $R_{\mathrm{S}}$ and $G_{\mathrm{S}}$ from the corresponding quantities measured in a horizontal plane, $R_{\mathrm{h}}$ and $G_{\mathrm{h}}$. Using standard geometrical relationships (e.g. Kondratyev, 1965; Robinson, 1966; Iqbal, 1983), the direct part of global radiation (sum of direct and diffuse radiation) received by the sloping surface, $I_{\mathrm{s}}$, can be approximated by

$$
I_{\mathrm{s}}=G_{\mathrm{h}}(1-d) \frac{\cos \beta \cos Z+\sin \beta \sin Z \cos (\Omega-\Theta)}{\cos Z},
$$

where $d$ is the diffuse portion of $G_{\mathrm{h}}, Z$ is the solar zenith angle, $\Omega$ is the solar azimuth angle and $\beta$ is the slope angle of the surface with an azimuth angle $\Theta$. We apply average slope angles below the pyranometers, although, strictly speaking, the assumption of a plane surface does not hold in the glacier environment. Local slope is difficult to define precisely, due to small-scale microtopographic variations, which also vary in time and generally become more pronounced as melt proceeds.

Strictly speaking, the diffuse components of global radiation as well as reflected radiation, which we assume to be

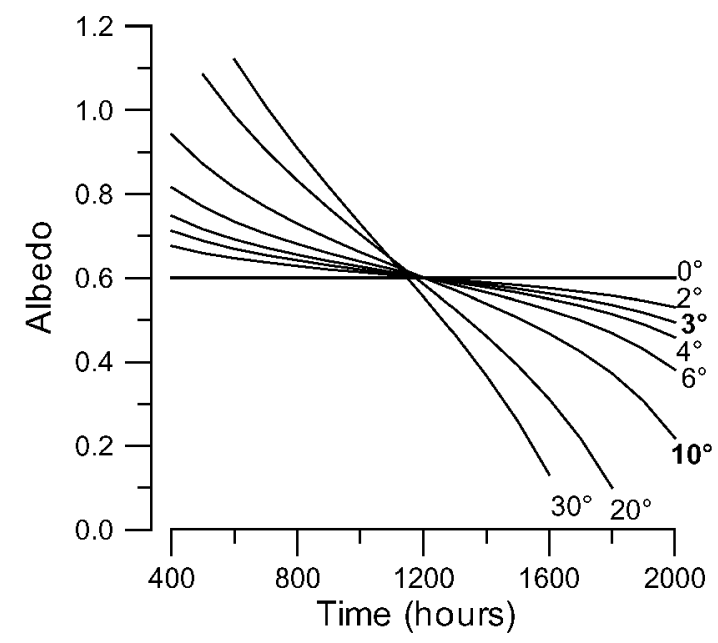

Fig. 2. Apparent albedo resulting from albedo being measured in a horizontal plane over inclined surfaces of different angles. The curves are based on Equation (3) using a true albedo of 0.6, a $90^{\circ}$ slope azimuth angle, 22 Fune, and the position of Storglaciären. Time is local standard time (LST).

isotropic, need to be corrected for surface slope considering ground reflection from surrounding topography and the effects of obstruction by the inclined surface. A full treatment of the problem is given in Kondratyev (1965). However, for the small surface-slope angles relevant for installing a climate station, these effects are negligibly small compared to those on the direct-beam radiation. An error analysis indicated a maximum error of $<1.5 \%$ for global radiation if such effects are neglected. We thus ignore these effects and approximate true albedo from

$$
\begin{aligned}
& \alpha_{\mathrm{t}}= \\
& \frac{R_{\mathrm{h}}}{G_{\mathrm{h}}(1-d) \frac{\cos \beta \cos Z+\sin \beta \sin Z \cos (\Omega-\Theta)}{\cos Z}+G_{\mathrm{h}} d} .
\end{aligned}
$$

In practice, application of Equation (3) often poses a problem, as the amounts of direct and diffuse radiation must be known individually, yet such data are rare. Often only global radiation is measured, and it is necessary to discriminate direct and diffuse components before applying Equation (3). For the analysis of individual clear-sky days, the diffuse portion of global radiation was assumed to be 0.15 as derived from radiation data $60 \mathrm{~km}$ east of Storglaciären (Hock, 1998). For separating direct and diffuse components of global radiation for all data, we used an empirical relationship relating the ratio of diffuse to global radiation, $d$, to the ratio of global to extraterrestrial solar radiation, $G / T$ (Hock, 1998). As cloudiness increases, $d$ will tend to increase, while the ratio $G / T$ will decrease, as less solar radiation will reach the surface. Since $T$ can be approximated from solar geometric relationships, this method allows global radiation to be split into the direct and diffuse components without cloud data. Hence, our correction scheme makes it possible to derive true albedo from horizontally measured shortwave radiation fluxes under all weather conditions.

The theoretical effect of surface tilt on horizontally measured albedo on a clear-sky day is illustrated for different slope angles in Figure 2. Calculations are based on a constant true albedo of 0.6 for the location of Storglaciären at summer solstice (22 June) assuming a slope azimuth 


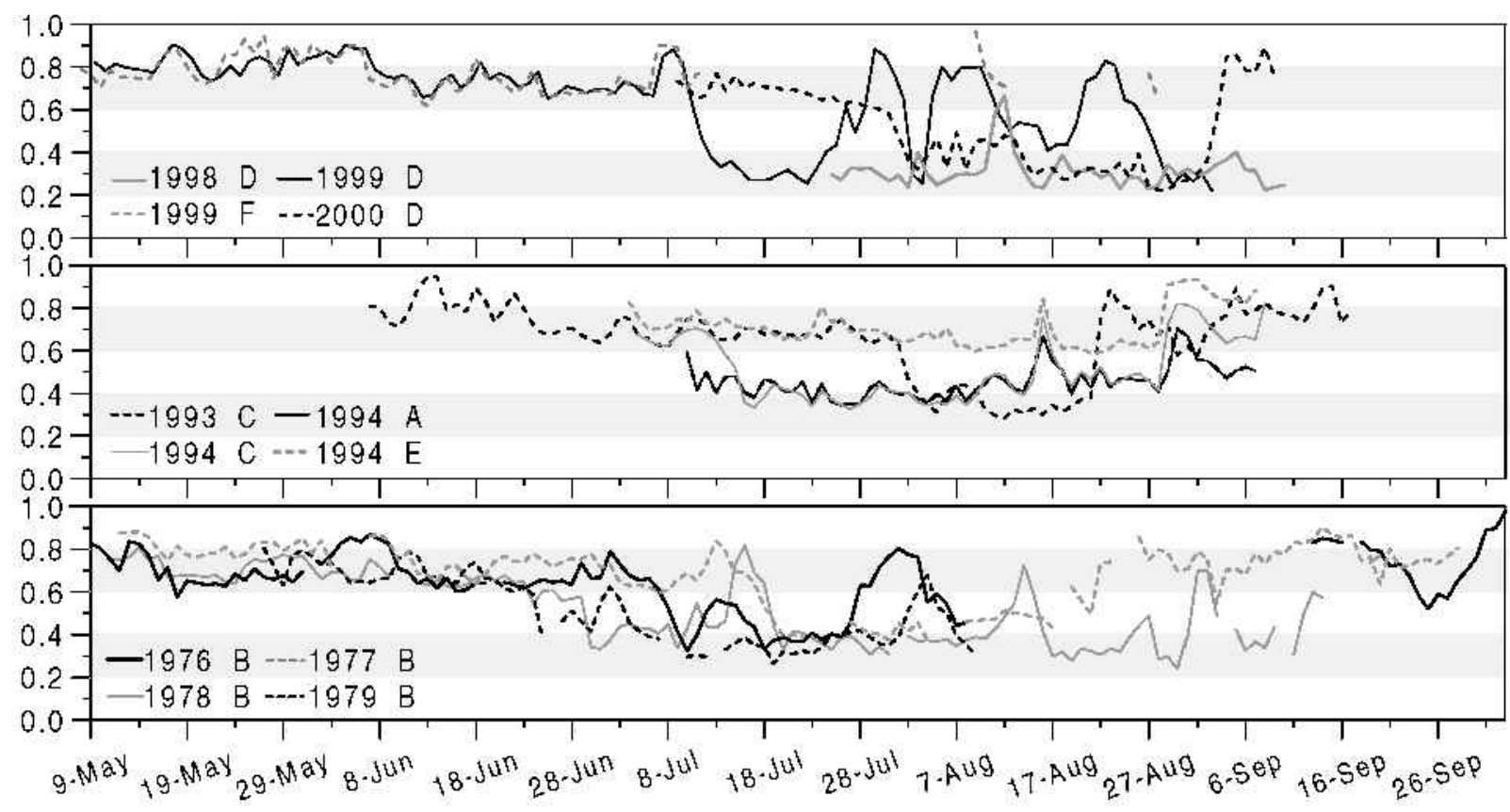

Fig. 3. Seasonal variation of daily mean albedo for 12 continuous records from Storglaciären, 1976-2000. Letters refer to the measurement sites (Fig. 1).

angle of $90^{\circ}$. True albedo is overestimated in the morning and underestimated in the afternoon, the deviation rapidly growing with increasing departure from noon and steepening slopes. For instance, within the period when zenith angles are $<65^{\circ}(\sim 0700-1730 \mathrm{~h})$, apparent albedo drops by 0.12 for a $3^{\circ}$ slope and 0.38 for a $10^{\circ}$ slope. It must be noted that the pattern of continuous drop of apparent albedo during the day is caused by the eastwards-sloping surface, as prevailing on Storglaciären. Hence, true direct solar radiation received by the inclined surface will be underestimated by the horizontally mounted instrument before solar noon, thus overestimating albedo, with the reverse applying after solar noon. However, the apparent symmetry will change with different slope azimuth angles (Mannstein, 1985). The slope effect is even more pronounced on any other day, as maximum sun-altitude angles are lower.

\section{RESULTS AND DISGUSSION}

\subsection{Seasonal and spatial variations}

Daily means of the 12 continuous albedo records obtained at various locations on Storglaciären between 1976 and 2000 are shown in Figure 3. Seasonal variations are dominated by the transition of snow to ice and vice versa. Sudden pronounced increases in albedo are common during most melt seasons and indicate summer snowfalls. Daily snow albedo fluctuated between 0.54 and 0.91 (Table 1), with a general trend of decreasing albedo as the melt seasons proceeded. Daily albedo over ice surfaces varied between 0.22 and 0.51 , although lacking any seasonal trend.

Figure 4 indicates how representative the continuous albedo records are for the entire ablation area. Albedo recorded at 17 sites throughout the ablation area in 1999 ranged from 0.06 at the sediment-covered site 5 on 1 September to a maximum of 0.84 at site 18 on 30 July after a snowfall. At sites with very high sediment concentration, ice albedo generally decreased through the season, if the periods of summer snowfall are discarded. A number of clean sites (1, 3, 6, 10; Fig. 4) tended to show significantly higher ice albedos than obtained at all AWSs, often exceeding 0.45 and reaching up to 0.59 (site 6). Although values are not directly comparable due to variations in other factors, such as cloudiness, these values are also somewhat higher than generally reported elsewhere for glaciers (e.g. Paterson, 1994; Cutler and Munro, 1996). These high albedo values are attributed to the location of the sites in an extended area characterized by clean, white ice, exhibiting much lower sediment concentrations than the locations of the AWSs. This implies that data collected at the weather stations are not representative for the central part of the ablation area, thus emphasizing the limitations of assuming that ice albedo measured at a single site is representative over the entire ice-exposed area, as is often done in distributed surface energy-balance models (e.g. Hock and Noetzli, 1997; EscherVetter, 2000). Although on average the error might cancel out, as other areas show significantly lower ice albedos due

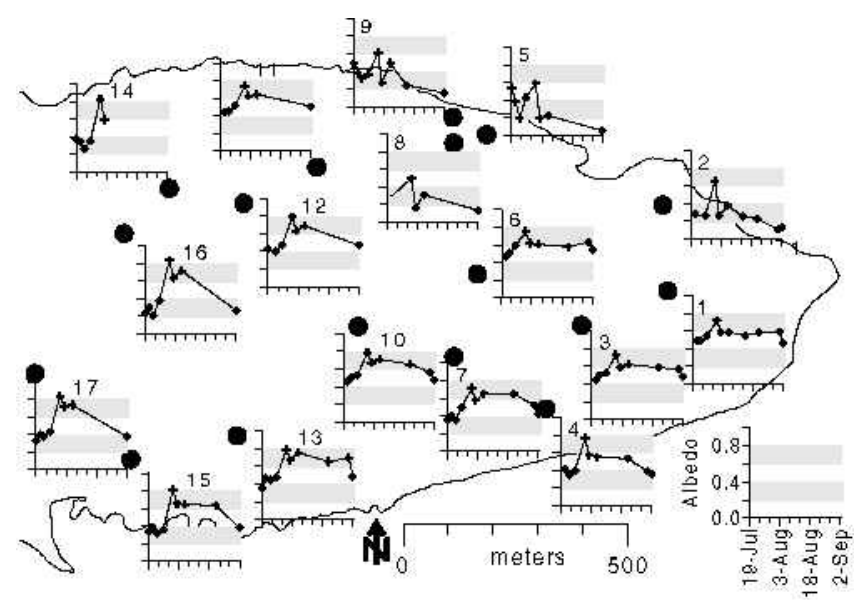

Fig. 4. Time series of results from portable albedo measurements at 17 sites, 18 July-2 September 1999. Several summer snowfalls occurred during this period. Crosses and squares denote measurements over snow and ice surfaces, respectively. 


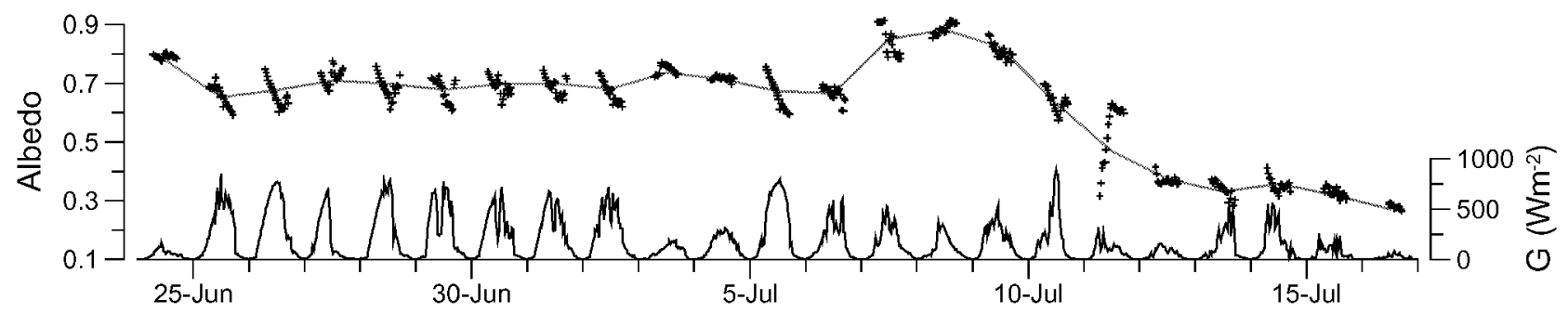

Fig. 5. Half-hourly albedo, $\alpha$ (crosses), daily mean albedo (upper line) and half-hourly global radiation, G (lower line), recorded at AWS D (Fig. 1), 24 June-16 July 1999. Half-hourly values with zenith angles $>65^{\circ}$ are not considered.

to high concentrations of sediment and debris, an error will be introduced into the spatial pattern of simulated melt.

\subsection{Diurnal variations and slope effect}

Figure 5 shows part of the half-hourly (non-slope-corrected) albedo record at AWS D in 1999, revealing a variety of different diurnal patterns. These range from hardly any variation to considerable variations during the course of the day. Negligible diurnal variations generally coincide with the occurrence of overcast sky or fog as indicated by relatively low global radiation values (Figs 5 and 6). On clear-sky days, albedo systematically dropped from morning to afternoon by up to 0.3 (Fig. 5). Comparing daily albedo cycles on clear-sky days derived from measurements of global radiation in a horizontal plane to those based on the readings from the instrument installed parallel to the surface (Fig. 7) reveals that the observed significant drop in albedo during the day is not real, but mainly a result of horizontal orientation of the pyranometer while the underlying surface is sloping. Horizontally measured albedo over frozen snow drops by approximately 0.15 on both clear-sky days considered, while albedo measured parallel to the surface slightly increased during the day. This increase may be attributed either to a small deviation of the instrument from the parallel plane or to imperfections of the instrument response to solar irradiances. Variations of the instrument constant could be caused by elevation (cosine) and azimuth errors and also by the tilt of the receiving surface (Wardle and others, 1996). Nevertheless, it is obvious that, on clear-

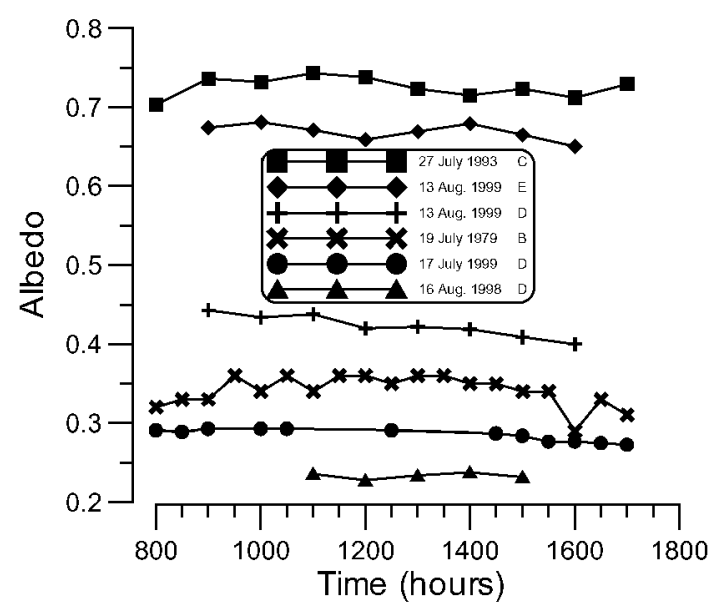

Fig. 6. Diurnal variation in albedo on foggy days. Missing data points are due to global radiation values $<30 \mathrm{Wm}^{-2}$ or zenith angles $>65^{\circ}$. Letters refer to the measurement sites (Fig. 1). Time is LST. sky days, surface slope significantly distorts results when measurements are made in a horizontal plane. Correcting for slope is even more important at high latitudes, since the error is amplified when moving towards the poles.

Correcting all continuous albedo records for the slope effect reveals that the difference in daily mean albedo measured horizontally and surface-parallel is generally negligible, reaching a maximum of $7 \%$. This is expected since overestimation of albedo in the mornings is generally compensated for by underestimation in the afternoons with a slope azimuth angle of $90^{\circ}$ (Fig. 2). However, on a diurnal basis, differences are considerable for clear-sky days (Fig. 8). Over frozen snow (Fig. 8a), the apparent drop in albedo by $>0.1$ during the day largely disappears and albedo hardly varies when data are corrected for the slope effect. Over melting snow and ice (Fig. 8b and c), daily variation in albedo becomes less pronounced when measurements are corrected for slope. The remaining drop in albedo is mainly attributed to changes in surface properties due to melt and associated increase in water at the surface. The refractive-index contrast between water and ice is small, but the presence of water increases effective grain-size and thus lowers albedo (Warren, 1982). The drop in albedo is particularly pronounced on 7 June 1999 (Fig. 8b), probably because it is the first day of surface melting after a period with frozen conditions.

\subsection{Effect of clouds}

A strong inverse relationship between global radiation and albedo was detected on days characterized by pronounced

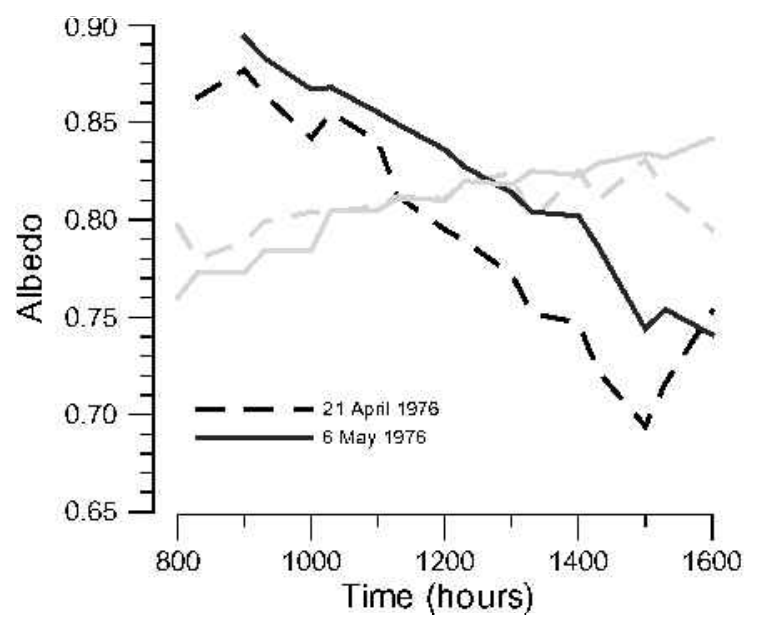

Fig. 7. Half-hourly albedo on 21 April and 6 May 1976, derived from a horizontally levelled (black line) and a parallellevelled instrument (greyline) at AWSB (Fig. 1). The surface slope is $\sim 5^{\circ}$. Time is LST. 


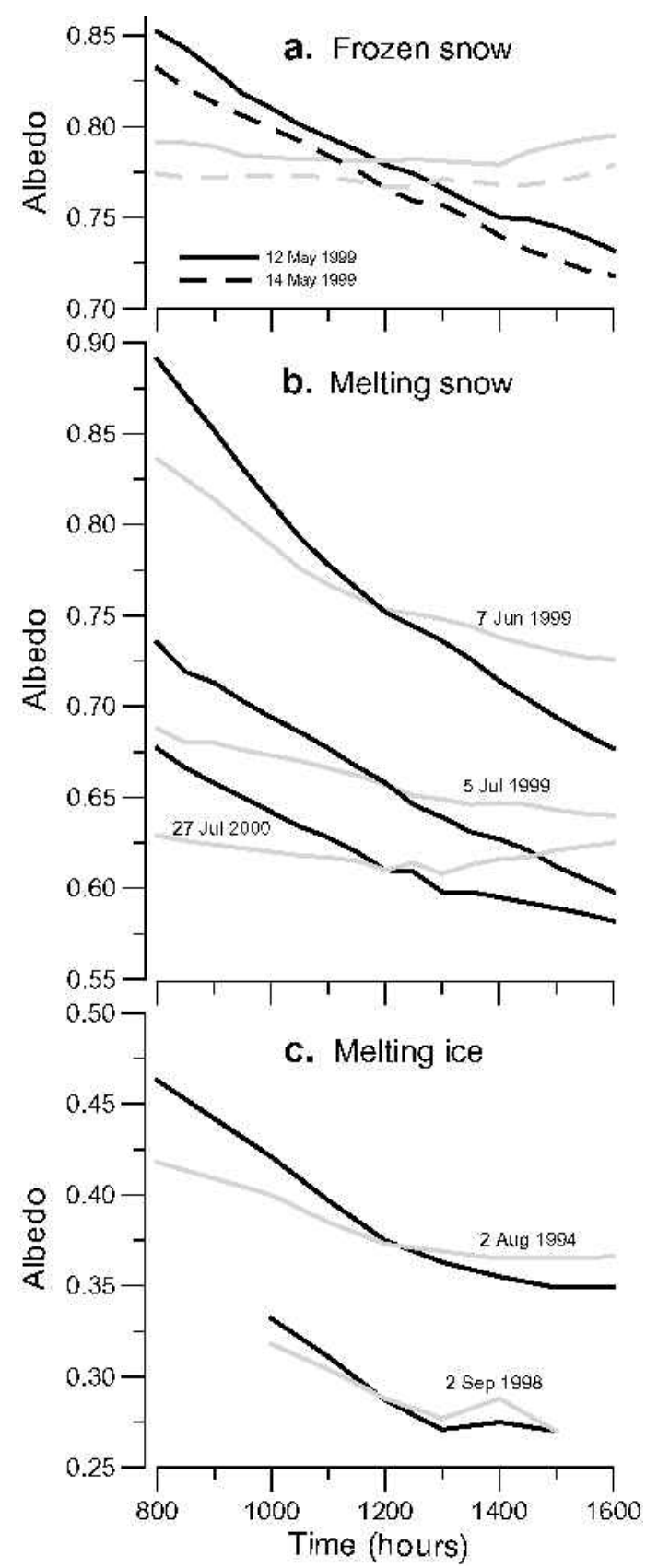

Fig. 8. Diurnal variation in albedo on clear-sky days based on measurement in a horizontal plane (black line) and after correcting for the sloping surface using Equation (3) (grey line). The surface slope is $\sim 3-4^{\circ}$. Time is LST.

cloud-cover fluctuations, as exemplified by 22 June 1998 (Fig. 9). Peaks in global radiation correspond to dips in the albedo record and vice versa, involving considerable shortterm albedo variability. For instance, within only 1 hour (1300-1400 h), albedo dropped from 0.78 to 0.66 , while global radiation increased from 115 to $605 \mathrm{~W} \mathrm{~m}^{-2}$. The following hour, albedo assumed 0.74 coincident with global radiation dropping to $203 \mathrm{~W} \mathrm{~m}^{-2}$. The distinct irregular short-term fluctuations in global radiation were caused by rapidly moving scattered clouds repeatedly screening the pyranometer from direct sunlight.

In order to quantify the dependence of albedo on clouds, we relate the percentage change in albedo between two successive measurements ( 0.5 or 1 hour, as available) to the corresponding change in the ratio of global radiation $(G)$ and

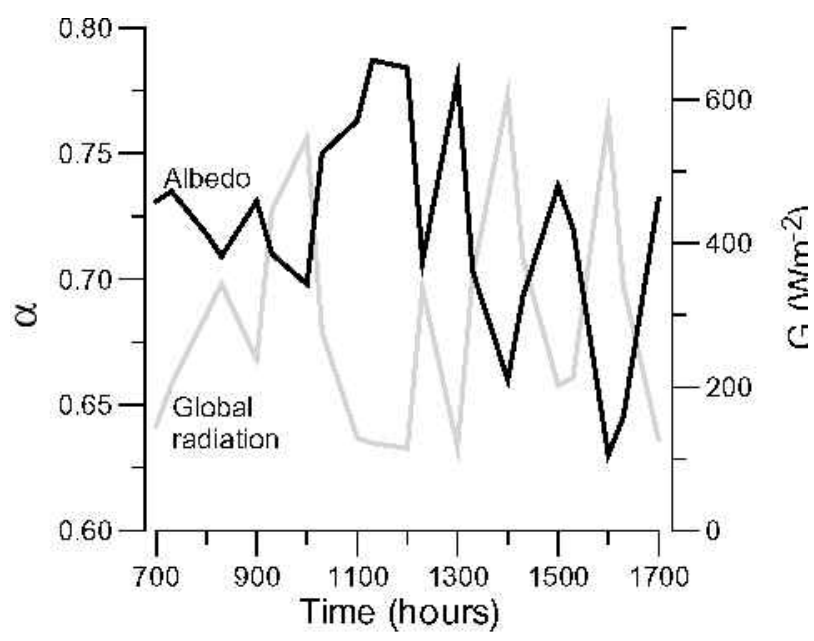

Fig. 9. Half-hourly albedo, $\alpha$, and global radiation, $G$, on 22 June 1998 at AWS D (Fig. 1). The surface consists of melting snow. Time is LST.

top-of-atmosphere solar radiation $(T)$. The ratio $G / T$ is taken as a measure of the diffuse portion of global radiation, and thus of cloudiness. The ratio is generally highest under clear-sky conditions and lowest under an overcast sky. A positive change, $\Delta(G / T)$, indicates decreasing cloudiness, while negative values correspond to increasing cloudiness. The analysis was performed separately for snow and ice surfaces. Days with snowfall and days with significant differences in albedo compared to the previous or following day were excluded, in order to reduce the influence of surface property changes on albedo. In addition, only days subject to a wide range in $\Delta(G / T)$ were considered, ensuring that significant cloud-cover changes had occurred.

Results indicate that over a snow surface, short-term albedo changes correlate well with $\Delta(G / T)\left(r^{2}=0.66\right.$; Fig. 10a). For individual days, $r^{2}$ varies between 0.5 and 0.9 . The relationship suggests that albedo can change by up to $10 \%$ as cloud cover varies within a day. For albedo variations within very short time periods ( 0.5 or 1 hour), it can be assumed that changes in surface properties are small. Hence, most of the observed short-term albedo variations can be attributed to changes in cloud cover. Over ice, the correlation displays larger scatter $\left(r^{2}=0.28\right)$, and the slope of the linear fit is much lower (Fig. 10b), indicating that the sensitivity of albedo to clouds is much weaker. This is attributed to the generally lower albedos of ice compared to those of snow, causing the effect of multiple reflection between the surface and the cloud base to be less efficient in enhancing albedo.

The analysis was repeated using daily time-steps, i.e. regressing changes in daily mean albedo against $\Delta(G / T)$ between successive days. Data from all years were considered, excluding periods with observed or assumed snowfalls. Over snow, the linear best fit yields almost the same slope as obtained for (half-) hourly time-steps, although the correlation is weaker $\left(r^{2}=0.42\right.$; Fig. 10c). A larger scatter is to be expected, as other factors influencing albedo are more likely to change on a daily basis. Nevertheless, $42 \%$ of observed daily mean albedo changes are explained by cloud effects as expressed by $\Delta(G / T)$, emphasizing the importance of cloud cover in albedo variations over snow surfaces. Over ice, no correlation between daily albedo changes and $\Delta(G / T)$ was observed (Fig. 10d). 

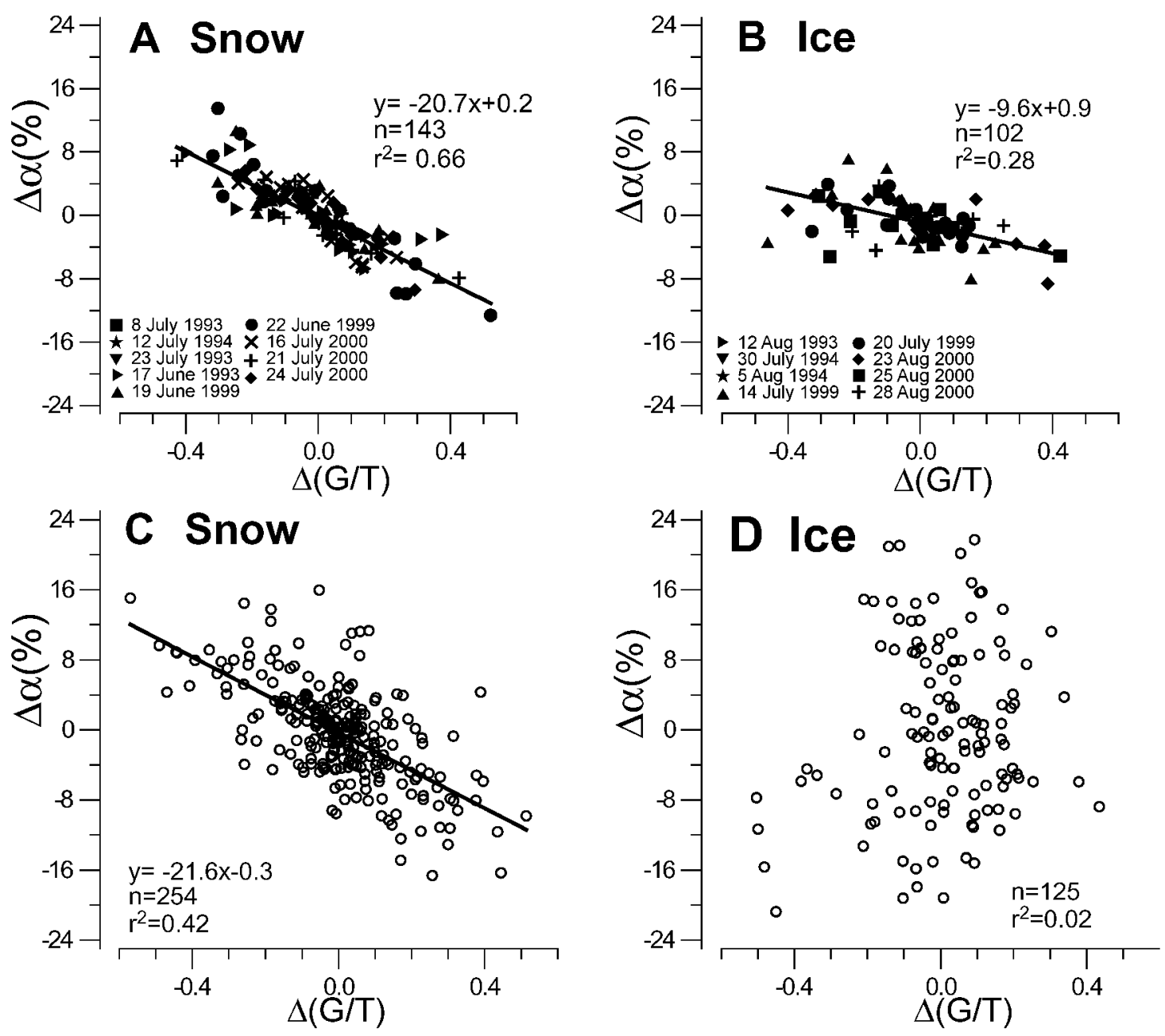

Fig. 10. Percentage change in albedo, $\Delta \alpha(\%)$, between successive (half-) hourly $(A, B)$ and mean daily $(C, D)$ measurements vs the corresponding change in the ratio of global to top-of-atmosphere radiation, $\Delta(G / T)$, over snow (mostly melting) and ice (melting). The correlations in A, B and C are significant at the 0.01 level.

\subsection{Ice albedo and surface characteristics}

Despite the low sensitivity of ice albedo to clouds, the day-today variability in albedo over ice was similar to that over snow (Fig. 10c and d), although obviously unrelated to cloud variations. This suggests that other mechanisms must be active. Spectrally resolved reflectivity measurements over ice indicate that variations are highest in the visible range and only minor in the near-infrared (Fig. 11). These results were obtained for glacier ice with typical, relatively low, sediment loads in the central part of the glacier close to station B (Fig. 1). Visible observations indicated more whitish ice for the D curve and more bluish ice for the $\mathrm{C}$ curve, and intermediate conditions for the two other curves. Thus, the albedo variability between ice surfaces may largely be due to reflectivity changes in the visible range. Since sediment and dust strongly absorb in the visible spectrum (Warren, 1982), the amount and distribution of sediments is crucial. We suggest that changes in characteristics of the uppermost surface ice layer, commonly referred to as "weathering crust", are mainly responsible for the observed variability in ice albedo at any given site. The physical properties of this layer, including its thickness, density, crystal structure, surface roughness and especially impurity content and stratification, are subject to continuous changes as the melt season proceeds. During periods of intense solar radiation, porosity will increase due to absorption of shortwave radiation below the surface, with resulting subsurface melting, whereas during subsequent cloudy, windy weather, the surface will tend to become glazed and hard (Müller and Keeler, 1969; Holmgren, 1971). Events such as rainfall will contribute to additional abrupt surface changes.

As related to prevailing weather conditions, these surface layer changes are expected to occur on a glacier-wide scale where glacier ice is exposed. Similarities in the evolution of ice-crust properties may explain why daily albedo variations at two different locations over ice (Fig. 3: 1994 A and $\mathrm{C}$ ) are strikingly parallel. A similar correspondence of daily albedo variations between two locations can be found over snow (Fig. 3: $1999 \mathrm{D}$ and F), but can largely be explained by the cloud dependence of albedo over snow. Hence, albedo variations between two sites go parallel in two instances, though for different physical reasons.

\section{GONGLUSIONS}

Albedo data collected on Storglaciären over nine melt seasons (1976-79, 1993-94, 1998-2000) were analyzed with respect to spatial and temporal variations. Snow albedo collected at weather stations, roughly varying between 0.6 and 0.9, exhibited a trend of decreasing albedo throughout the melt seasons, as snowmelt, metamorphic processes and accumulation of sediment and dust increase in importance. During periods of exposed ice, daily mean albedo did not 


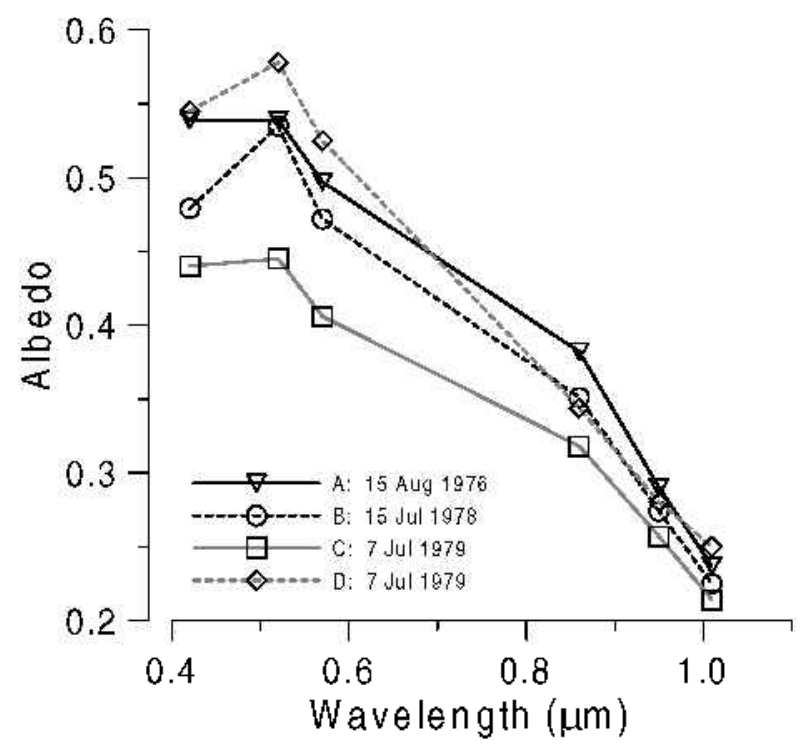

Fig. 11. Reflectivity for different wavelengths at four sites over ice in the vicinity of weather station B (Fig. 1).

show any seasonal trends, although fluctuating roughly between 0.25 and 0.4 . Portable albedo measurements revealed that wide areas in the ablation area show significantly higher ice albedos $(\sim 0.45-0.6)$ than generally obtained at the weather stations or reported in other studies, which may be a result of the dominance of clean white ice in these areas. Variations in ice albedo between sites exceeded daily variability at weather stations, posing a problem for gridbased modelling of absorbed shortwave radiation in melt models. Models assuming ice albedo to be spatially constant or to vary with elevation will result in erroneous estimates of spatially distributed melt. Further research needs to be directed to capturing the enormous spatial heterogeneity of albedo by remote-sensing methods. However, the temporal representativeness of satellite-derived albedo is limited, and, in the case of Storglaciären, further reduced by persistent cloudy/overcast conditions and a relatively short period when glacier ice is exposed.

Diurnal variations in albedo were generally negligible on overcast or foggy days, while on clear-sky days a striking continuous drop in albedo by up to 0.3 , from high values in the morning to low values in the afternoon, was observed when albedo was computed from measurements performed in a horizontal plane. However, much of the observed diurnal variation is not real, but rather a result of the instrument being levelled horizontally while the surface is inclined. When we correct for this effect, over frozen glacier surfaces the drop in albedo largely disappears, while over melting surfaces it is considerably diminished. The remaining drop in albedo is largely explained by increasing water content due to melt. The symmetry of the apparent diurnal albedo pattern suggests that albedo retrieved at midday best represents the daily mean. However, it must be emphasized that the specific symmetry found on Storglaciären, characterized by a continuous drop during the day, is a result of the glacier surface being inclined almost perfectly to the east. Results clearly indicate that under clear-sky conditions, even for small slope angles $\left(<5^{\circ}\right)$, the effect of slope on horizontally measured albedo is significant and must be taken into account before diurnal albedo variations can be interpreted and used as input in high-resolution melt models or as ground truth for satellite-derived albedos.
Short-term diurnal albedo fluctuations exceeding 0.1 were observed over snow on partly cloudy days as a result of the effects of clouds. Albedo changes between successive time-steps ( 0.5 or 1 hour) were correlated with corresponding changes in the ratio of global radiation and top-ofatmosphere solar radiation; the ratio is taken as a measure for cloudiness. These quantities correlate well over melting snow $\left(r^{2}=0.66\right)$, even for daily time-steps $\left(r^{2}=0.42\right)$, while correlation is weak or lacking over ice surfaces. The different response over snow and ice is attributed to lower efficiency of the effects of multiple reflection in enhancing albedo, as albedo over ice is generally much lower than over snow. The results emphasize the need to incorporate the effects of clouds into albedo parameterizations in numerical energybalance models, a dependency commonly neglected. However, snow and ice surfaces must be treated separately to account for the significantly lower sensitivity of ice albedo to cloud-cover variations. This is important in future predictions of glacier melt to properly account for feedback mechanisms, since the area where ice is exposed may change under a changing climate. The cloud effect can be included in models by expressing total albedo as a function of cloud cover or other dependent quantities (e.g. the ratio of global radiation to top-of-atmosphere radiation), or alternatively by treating albedo in several spectral bands, which is a current trend in general circulation model (GCM) modelling (Roesch and others, 2002)).

Although sensitivity of ice albedo to clouds was low, the day-to-day variability in ice albedo was similar to that over snow. This is attributed to changes in the characteristics of the uppermost surface ice layer related to prevailing weather conditions, and thus occurring at a glacier-wide scale. Further research is needed to establish the physical controls of such changes in surface characteristics by combining albedo measurements with detailed surface surveys, weather data and observations.

Albedo measurements on glaciers require considerable effort in order to obtain a sufficiently large and accurate dataset that allows for quantitatively relating spatial and temporal albedo changes to their causes. Such datasets are rare, so there is still a need for detailed albedo datasets on glaciers to develop and verifiy glacier albedo parameterizations at the glacierwide scale and to provide ground truth for satellite-derived albedos. The use of our dataset for developing and testing albedo parameterizations will be considered in future work.

\section{ACKNOWLEDGEMENTS}

Financial support was given by the C. Mannerfelts foundation, the Linné foundation, European Union regional development funds for northern Sweden, the Swedish Research Council and "Kommission für Reisestipendien der Schweizerischen Akademie der Naturwissenschaften”. T. Carlund is gratefully acknowledged for providing the ventilation system for the pyranometers. Comments on the manuscript by P. Jansson, T. Konzelmann, A. Ohmura and an anonymous reviewer considerably improved the paper. We thank J.W. Glen and M. Sturm for their work as scientific and chief editor, respectively.

\section{REFERENGES}

Ambach, W. 1963. Untersuchungen zum Energieumsatz in der Ablationszone des grönländischen Inlandeises (Camp IV - EGIG, 69 $40^{\prime} 05^{\prime \prime} \mathrm{N}$, 
$49^{\circ} 37^{\prime} 58^{\prime \prime}$ W). Medd. Grønl., 174(4).

Arendt, A. 1999. Approaches to modelling the surface albedo of a high Arctic glacier. Geogr. Ann., 81A(4), 477-487.

Bintanja, R. and M. R. van den Broeke. 1996. The influence of clouds on the radiation budget of ice and snow surfaces in Antarctica and Greenland in summer. Int. f. Climatol., 16(11), 1281-1296.

Brock, B.W., I. C. Willis and M. J. Sharp. 2000. Measurement and parameterization of albedo variations at Haut Glacier d'Arolla, Switzerland. F. Glaciol., 46(155), 675-688.

Carroll, J. J. and B.W. Fitch. 1981. Effects of solar elevation and cloudiness on snow albedo at the South Pole. 7. Geophys. Res., 86(C6), 5271-5276.

Cutler, P. M. and D. S. Munro. 1996. Visible and near-infrared reflectivity during the ablation period on Peyto Glacier, Alberta, Canada. F. Glaciol., 42(141), 333-340.

Dirmhirn, I. and F. D. Eaton. 1975. Some characteristics of the albedo of snow. 7. Appl. Meteorol., 14(3), 375-379.

Escher-Vetter, H. 2000. Modelling meltwater production with a distributed energy balance method and runoff using a linear reservoir approach: results from Vernagtferner, Oetztal Alps, for the ablation seasons 1992 to 1995. Z. Gletscherkd. Glazialgeol., 36, 119-150.

Garratt, J. R., D. M. O'Brian, G. L. Stephens, M. R. Dix, M. Wild and J. M. Murphy. 1999. Response of radiative fluxes in the atmosphere to $\mathrm{CO}_{2}$ forcing. Global Planet. Change, 20(1), 33-55.

Grenfell, T. C., S. G. Warren and P. G. Mullen. 1994. Reflection of solar radiation by the Antarctic snow surface at ultraviolet, visible, and near-infrared waveleng ths. F. Geophys. Res., 99(D9), 18,669-18,684.

Greuell, W. and W. H. Knap. 2000. Remote sensing of the albedo and detection of the slush line on the Greenland ice sheet. F. Geophys. Res., 105(D12), $15,567-15,576$.

Greuell, J.W. and T. Konzelmann. 1994. Numerical modeling of the energy balance and the englacial temperature of the Greenland ice sheet: calculations for the ETH-Camp location (West Greenland, $1155 \mathrm{~m}$ a.s.l.). Global Planet. Change, 9(1-2), 91-114.

Greuell, W. and J. Oerlemans. 1986. Sensitivity studies with a mass balance model including temperature profile calculations inside the glacier. $Z$ Gletscherkd. Glazialgeol., 22(2), 101-124.

Grudd, H. and T. Schneider. 1996. Air temperature at Tarfala Research Station 1946-1995. Geogr. Ann., 78A(2-3), 115-120.

Hock, R. 1998. Modelling of glacier melt and discharge. Zürcher Geogr. Schr. 70.

Hock, R. 1999. A distributed temperature-index ice- and snowmelt model including potential direct solar radiation. f. Glaciol., 45(149), 101-111.

Hock, R. and B. Holmgren. 1996. Some aspects of energy balance and ablation of Storglaciären, northern Sweden. Geogr. Ann., 78A(2-3), 121-131.

Hock, R. and C. Noetzli. 1997. Areal melt and discharge modelling of Storglaciären, Sweden. Ann. Glaciol., 24, 211-216.

Hock, R., J. Carrivick and U. Jonsell. 2000. Glacio-meteorological studies on Storglaci5ren in 1999. In Klingbjer, P., ed. Tarfala Research Station, annual report 1998-99. Stockholm, University of Stockholm. Department of Physical Geography, 20-23. (Forskningsrapport 111.)

Holmgren, B. 1971. Climate and energy exchange on a sub-polar ice cap in summer. Arctic Institute of North America Devon Island Expedition 1961-1963. Part E. Radiation climate. Uppsala, Uppsala Universitet. Meteorologiska Institutionen. (Meddelande 111.

Hubley, R. C. 1955. Measurements of diurnal variations in snow albedo on Lemon Creek Glacier, Alaska. F. Glaciol., 2(18), 560-563

Iqbal, M. 1983. An introduction to solar radiation. New York, Academic Press.

Key, J. R., X. Wang, J. C. Stroeve and C. Fowler. 2001. Estimating the cloudysky albedo of sea ice and snow from space. 7. Geophys. Res., 106(D12), 12,489-12,497.

Knap, W. H., B.W. Brock, J. Oerlemans and I. C. Willis. 1999a. Comparison of Landsat TM-derived and ground-based albedos of Haut Glacier d'Arolla, Switzerland. Int. 7. Remote Sensing, 20(17), 3293-3310
Knap, W. H., C. H. Reijmer and J. Oerlemans. 1999b. Narrowband to broadband conversion of Landsat TM glacier albedos. Int. 7. Remote Sensing, 20(10), 2091-2110.

Kondratyev, K. Ya. 1965. Radiative heat exchange in the atmosphere. Oxford, etc., Pergamon Press.

Konzelmann, T. and A. Ohmura. 1995. Radiative fluxes and their impact on the energy balance of the Greenland ice sheet. F. Glaciol., 41(139), 490-502.

LI-COR. 1991. LI-COR terrestrial radiation sensors, type SA instruction manual. Lincoln, NE, LI-COR Inc. (Publ. 8609-56,

Liljequist, G. H. 1956. Energy exchange of an Antarctic snow-field. NorwegianBritish-Swedish Antarctic Expedition, 1949-52 Sci. Results II, Part 1.

Mannstein, H. 1985. The interpretation of albedo measurements on a snow covered slope. Arch. Meteorol. Geophys. Bioklimatol., Ser. B, 36(1), 73-81.

Marshall, S. E. and S. G. Warren. 1987. Parameterization of snow albedo for climate models. International Association of Hydrological Sciences Publication 166 (Symposium at Vancouver 1987 — Large Scale Effects of Seasonal Snow Cover), 43-50.

Müller, F. and C. M. Keeler. 1969. Errors in short-term ablation measurements on melting ice surfaces. F. Glaciol., 8 (52), 91-105.

Müller, H. 1985. Review paper on the radiation budget in the Alps. F. Climatol., 5(4), 445-462.

Oerlemans, J. 1992. Climate sensitivity of glaciers in southern Norway: application of an energy-balance model to Nigardsbreen, Hellstugubreen and Alfotbreen. F. Glaciol., 38(129), 223-232

Oerlemans, J. and N. C. Hoogendoorn. 1989. Mass-balance gradients and climatic change. f. Glaciol., 35(121), 399-405.

Oerlemans, J. and W. H. Knap. 1998. A 1 year record of global radiation and albedo in the ablation zone of Morteratschgletscher, Switzerland. 7. Glaciol., 44(147), 231-238

Ohmura, A. 1981. Climate and energy balance on Arctic tundra, Axel Heiberg Island, Canadian Arctic Archipelago, spring and summer 1969, 1970 and 1972. Zürcher Geogr. Schr. 3.

Olsson, H. 1936. Radiation measurements on Isachsen's plateau. Geogr. Ann., 18(3-4), 225-244.

Paterson, W. S. B. 1994. The physics of glaciers. Third edition. Oxford, etc., Elsevier Reijmer, C. H., W. H. Knap and J. Oerlemans. 1999. The surface albedo of the Vatnajökull ice cap, Iceland: a comparison between satellite-derived and ground-based measurements. Boundary-Layer Meteorol., 92(1), 125-144.

Robinson, N., ed. 1966. Solar radiation. New York, Elsevier Publishing Company.

Roesch, A., M. Wild, R. Pinker and A. Ohmura. 2002. Comparison of spectral surface albedos and their impact on the general circulation model simulated surface climate. F. Geophys. Res., 107(D14). (10.1019/2001JD000809.)

Sauberer, F. and I. Dirmhirn. 1952. Der Strahlungshaushalt horizontaler Gletscherflächen auf dem hohen Sonnblick. Geogr. Ann., 34(3-4), 261-290.

Sicart, J. E., P. Ribstein, P. Wagnon and D. Brunstein. 2001. Clear-sky albedo measurements on a sloping glacier surface: a case study in the Bolivian Andes. F. Geophys. Res., 106(D23), 31,729-31,738.

Van de Wal, R. S. W., J. Oerlemans and J. C. van der Hage. 1992. A study of ablation variations on the tongue of Hintereisferner, Austrian Alps. $\mathcal{F}$. Glaciol., 38(130), 319-324.

Wardle, D. I. and 8 others. 1996. Improved measurements of solar irradiance by means of detailed pyranometer characterization. Report of task 9. Solar radiation and pyranometry. Ont., International Energy Agency. (Report IEA-SHCP-9C-12.

Warren, S. G. 1982. Optical properties of snow. Rev. Geophys. Space Phys., 20(1), 67-89.

Wendler, G. andJ. Kelley. 1988. On the albedo of snow in Antarctica: a contribution to I.A.G.O. F. Glaciol., 34(116), 19-25.

Winther, J.-G. 1993. Landsat TM derived and in situ summer reflectance of glaciers in Svalbard. Polar Res., 12(1), 37-55.

Wiscombe, W. J. and S. G. Warren. 1980. A model for the spectral albedo of snow. I. Pure snow. f. Atmos. Sci., 37(12), 2712-2733. 